\title{
Case Report \\ Successful Management of Immune Thrombocytopenia Presenting with Lethal Alveolar Hemorrhage
}

\author{
Keiki Nagaharu (D), ${ }^{1,2}$ Masahiro Masuya, ${ }^{1}$ Keiki Kawakami ${ }^{D}{ }^{2}$ and Naoyuki Katayama ${ }^{1}$ \\ ${ }^{1}$ Department of Hematology and Oncology, Mie University Graduate School of Medicine, Edobashi 2-174, Tsu, \\ Mie Prefecture 514-8507, Japan \\ ${ }^{2}$ Department of Hematology and Oncology, Suzuka General Hospital, Yamanohana 1275-53, Suzuka, \\ Mie Prefecture 513-8630, Japan \\ Correspondence should be addressed to Keiki Nagaharu; keiki.nagaharu@gmail.com
}

Received 9 April 2019; Accepted 22 May 2019; Published 10 June 2019

Academic Editor: Tomás J. González-López

Copyright (c) 2019 Keiki Nagaharu et al. This is an open access article distributed under the Creative Commons Attribution License, which permits unrestricted use, distribution, and reproduction in any medium, provided the original work is properly cited.

\begin{abstract}
Immune thrombocytopenic purpura (ITP) typically presents with bleeding due to immunologic thrombocytopenia. Severe hemorrhage due to ITP is sometimes lethal, and the urgent recovery of platelets is necessary. In addition to conventional therapeutic strategies, romiplostim shows promising efficacy for chronic ITP. However, there is little evidence for the utilization of this treatment for acute ITP or acute exacerbation of chronic ITP. We report the case details of three elderly ITP patients presenting with lethal diffuse alveolar hemorrhage. These patients had the following underlying pulmonary diseases: case 1, nontuberculous mycobacterial infection and sarcoidosis; case 2, cryptogenic organizing pneumonia; case 3, pulmonary emphysema. These patients recovered following treatment with romiplostim at a higher dose $(10 \mu \mathrm{g} / \mathrm{kg})$, in addition to conventional therapies including corticosteroids and high-dose intravenous immunoglobulin. In summary, the addition of romiplostim resulted in earlier recovery of thrombocytopenia than has been previously reported. Our three cases suggest that early romiplostim at a higher dose could be an efficacious therapeutic option for acute ITP patients with severe lethal bleeding.
\end{abstract}

\section{Introduction}

Immune thrombocytopenic purpura (ITP) is a hematological disorder characterized by thrombocytopenia due to immunological mechanisms. Lethal bleeding symptoms (e.g., intracranial, gastrointestinal, and diffuse alveolar hemorrhage $(\mathrm{DAH})$ ) have been reported as severe complications in ITP [1]. Standard first-line therapy for ITP is corticosteroids, with or without high-dose intravenous immunoglobulin (IVIG). In cases refractory to these therapies, splenectomy or treatment with rituximab is recommended [2-4]. Recently, romiplostim has been reported as an additional strategy [5]. In chronic ITP, weekly subcutaneous administration of romiplostim increased the platelet count without significant adverse effects [6, 7]. However, few reports have focused on early care with romiplostim for newly diagnosed patients or cases of acute exacerbation of ITP $[8,9]$. We report three elderly ITP patients presenting with lethal DAH. These cases were successfully treated with romiplostim at a higher dose, in addition to conventional therapies. Through our cases, we suggest the efficacy of romiplostim at a higher dose against lethal hemorrhage.

\section{Case Presentation}

2.1. Case 1. A 65-year-old male was admitted to our hospital because of ecchymosis on both lower extremities. Three years before admission, he was diagnosed with ITP by laboratory tests, including antibodies against platelet glycoprotein (GP) IIb/IIIa and GP IV, and bone marrow aspiration. He had been treated successfully with corticosteroids. History included nontuberculosis mycobacterial infection. Previous treatment included prednisolone 
(PSL; $5 \mathrm{mg} /$ day), clarithromycin, rifampicin, and ethambutol hydrochloride. Two weeks before admission, routine laboratory examination showed normal platelet counts (PC; $\left.185 \times 10^{9} / 1\right)$.

On admission, laboratory findings showed a PC of $3.0 \times 10^{9} / 1$. Biochemical parameters and coagulation values were within the normal limit. Antibodies against Helicobacter pylori, hepatitis $\mathrm{C}$ virus ( $\mathrm{HCV})$, hepatitis $\mathrm{B}$ virus (HBV), and human immunodeficiency virus (HIV) were negative. We diagnosed him with acute exacerbation of chronic ITP. The clinical course is shown in Supplementary Figure 1.

He was treated immediately with high-dose IVIG, PSL (40 mg/day, p.o.), and romiplostim ( $1 \mu \mathrm{g} / \mathrm{kg})$. During the next four days, he developed respiratory failure; $\mathrm{PaO}_{2} / \mathrm{FiO}_{2}$ ratio was approximately 250 . On the fourth day of hospitalization, computed tomography (CT) revealed groundglass opacities (GGOs) with marginal infiltration in both lung fields, on the basis of which a diagnosis of alveolar hemorrhage was made. His dyspnea worsened gradually, and noninvasive positive pressure ventilation (NPPV) was initiated.

On the $11^{\text {th }}$ day of hospitalization, a higher dose of romiplostim $(10 \mu \mathrm{g} / \mathrm{kg})$ was initiated together with pulsed doses of methyl-PSL (1000 mg/day for 3 days) and a second cycle of IVIG. His PC recovered by the $21^{\text {st }}$ day of hospitalization, and he was discharged without any complications. The patient's PC has remained normal whilst being treated with $12.5 \mathrm{mg}$ of PSL daily for 12 months, without recurrence of alveolar hemorrhage.

2.2. Case 2. A 71-year-old male was referred to our hospital because of gingival bleeding, hemoptysis, and dyspnea. His past medical history included acute HBV infection during the pediatric period, which resolved without any prolonged hepatic disorders. Three months prior to admission, chest radiography showed a consolidation in the right lung field. Two days before admission, he underwent transbronchial lung biopsy and was diagnosed with cryptogenic organizing pneumonia.

The patient's PC was low $\left(6.0 \times 10^{9} / 1\right)$ at admission, despite a normal PC $\left(224 \times 10^{9} / 1\right)$ at 12 days before admission. Platelet-associated IgG increased to $81.7 \mathrm{ng} / 10^{7}$ cells, and tests for antibodies against GP IIb/IIIa and GP Ia/IIa were positive. Serological tests for $\mathrm{H}$. pylori, HCV, and, HIV were negative but positive for anti-HBs antibody, without viremia. Bone marrow examination showed an increased number of megakaryocytes, without apparent malignancy. CT at admission revealed pulmonary bilateral GGOs. The patient was diagnosed as having acute ITP with alveolar hemorrhage.

High-dose IVIG was started with PSL $(0.5 \mathrm{mg} / \mathrm{kg}$, p.o.); however, he developed dyspnea on the second day of hospitalization (Supplementary Figure 1). Given the risk for respiratory failure, a higher dose of romiplostim $(10 \mu \mathrm{g} / \mathrm{kg} / \mathrm{w})$ was initiated. Nine days after admission, his $\mathrm{PC}$ increased to $9.0 \times 10^{9} / 1$ and respiratory symptoms resolved. On the $30^{\text {th }}$ day after admission, he was discharged without any complications.
2.3. Case 3. A 71-year-old male was admitted because of dyspnea and hemoptysis. He had a history of StevensJohnson syndrome due to salazosulfapyridine and pulmonary emphysema. On admission, he developed severe respiratory failure (P/F ratio: 100) and NPPV support was initiated. His PC was low $\left(2.0 \times 10^{9} / \mu \mathrm{l}\right)$ at admission but had been normal $\left(158 \times 10^{9} / 1\right)$ two months before. Laboratory tests showed high PA-IgG $\left(605.8 \mathrm{ng} / 10^{7}\right.$ cells $)$, and serological tests for $H$. pylori, HCV, HBV, and HIV were negative. Bone marrow examination revealed an increase in the number of megakaryocytes without malignancies. CT on the day of admission revealed GGOs with no evidence of infection. He was diagnosed as having acute ITP with alveolar hemorrhage.

The patient was treated with methyl-PSL pulse therapy (1000 mg daily for 5 days) and IVIG (Supplemental Figure 1). Rapid progression of severe respiratory failure occurred over the next two days; hence, we added romiplostim at a higher dose $(10 \mu \mathrm{g} / \mathrm{kg}$ weekly). Four days after initiating treatment, his PC increased to $25 \times 10^{9} / 1$ and hemoptysis and dyspnea resolved. Despite tapering of the PSL dose, there was no recurrence of thrombocytopenia.

\section{Discussion}

The causes of DAH are heterogeneous: vasculitis, druginduced lung injury, stem cell transplantation, infection, trauma, coagulopathy, and thrombocytopenia [10, 11]. The prognosis of thrombocytopenia-related DAH is especially poor [12]. ITP patients with DAH are rare although are described in several case reports [13-17]. Although these cases have no apparent relationship with pulmonary diseases, our three patients had underlying pulmonary diseases, in addition to thrombocytopenia. Clinicians should consider the importance of DAH in ITP with underlying lung diseases.

IVIG and corticosteroids are reported to result in recovery in approximately 2 days and 2-5 days, respectively [1]. Alternative strategies including splenectomy and/or thrombopoietin receptor agonists should be considered in refractory cases. The usual initiation dose of romiplostim is $1.0 \mu \mathrm{g} / \mathrm{kg}$, and dose adjustment is necessary to achieve PC responses. The standard initiation dose is not sufficient in many cases. Indeed, Shirasugi et al. reported that treatment with an initial dose of 3 to $6 \mu \mathrm{g} / \mathrm{kg}$ promotes more rapid platelet recovery compared with that of $1.0 \mu \mathrm{g} / \mathrm{kg}$ in chronic ITP [18]. In addition, Contis et al. showed that higher doses $(6-9 \mu \mathrm{g} / \mathrm{kg})$ of romiplostim might be needed in patients with severe acute or persistent ITP, who are refractory to conventional therapies [8]. These findings indicated that the higher dose is effective for lethal cases.

Our cases showed a more rapid response, compared with previous cases with available clinical data [15-17] (Figure 1). Despite having a much higher platelet count (600 to $1000 \times 10^{9} / 1$ ) after treatment (Supplementary Figure 1), no vascular thrombosis was observed in all cases. These cases indicated that early and higher doses of romiplostim can be effective for ITP with lethal hemorrhage. Further investigations will be needed to establish the appropriate dose 


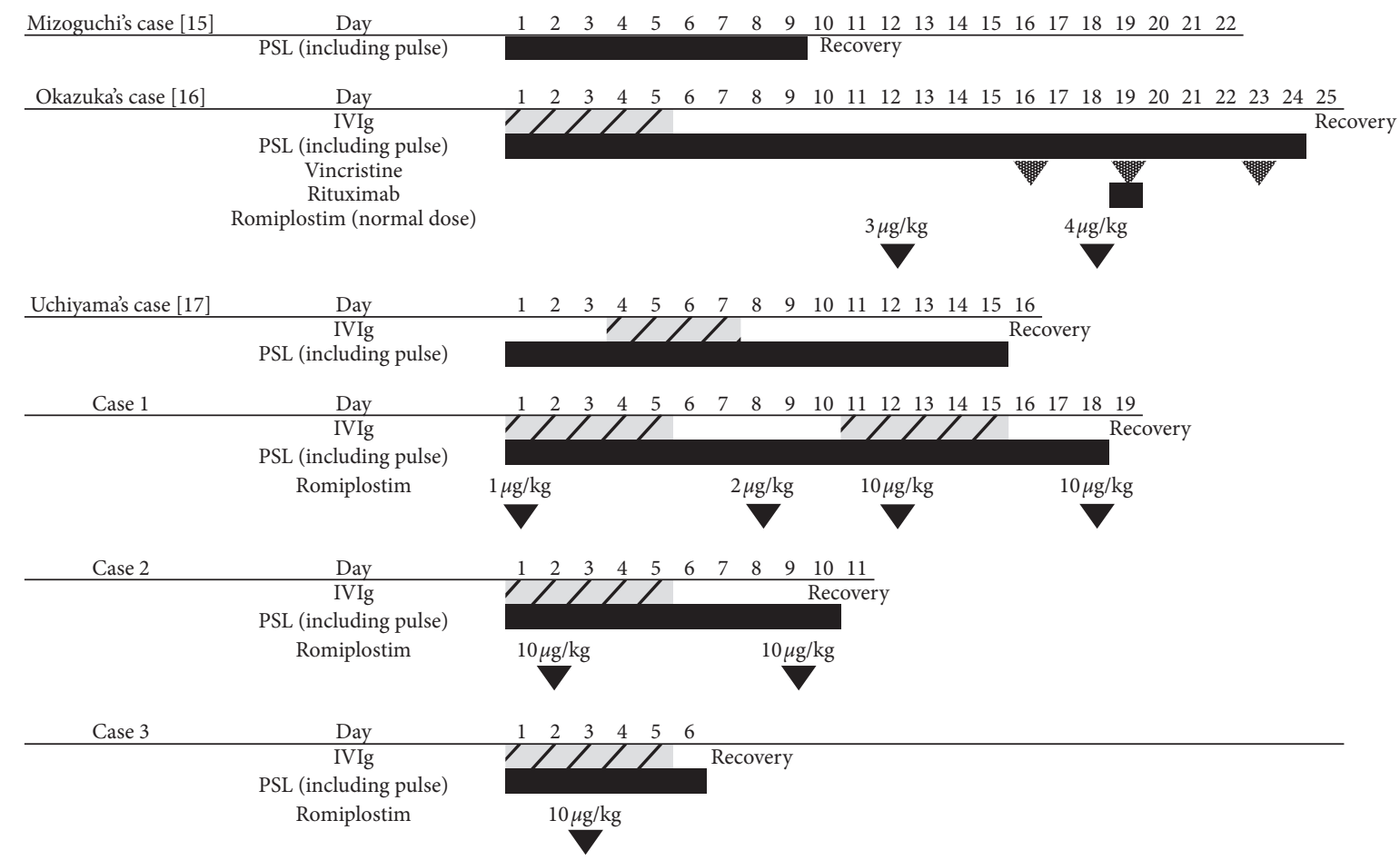

FIgURE 1: Literature review of the cases with DAH due to ITP. Recovery is defined as a platelet count of more than $100 \times 10^{9} / 1$.

of romiplostim for patients with ITP presenting with lethal hemorrhage.

\section{Conflicts of Interest}

The authors declare that they have no conflicts of interest.

\section{Acknowledgments}

We would like to thank Editage (http://www.editage.jp) for English language editing.

\section{Supplementary Materials}

Supplementary Figure 1 shows clinical course of our 3 cases. (Supplementary Materials)

\section{References}

[1] D. M. Arnold, "Bleeding complications in immune thrombocytopenia," Hematology American Society of Hematology Education Program, vol. 2015, no. 1, pp. 237-242, 2015.

[2] Z. Zhou and R. Yang, "Rituximab treatment for chronic refractory idiopathic thrombocytopenic purpura," Critical Reviews in Oncology/Hematology, vol. 65, no. 1, pp. 21-31, 2008.

[3] W. A. Hammond, E. M. Rodriguez, Z. Li et al., "Splenectomy or rituximab in steroid-refractory immune thrombocytopenia (ITP): the mayo clinic experience," Blood, vol. 128, p. 3735, 2016.

[4] S. Chaturvedi, D. M. Arnold, and K. R. McCrae, "Splenectomy for immune thrombocytopenia: down but not out," Blood, vol. 131, no. 11, pp. 1172-1182, 2018.

[5] C. Neunert, W. Lim, M. Crowther, A. Cohen, L. Solberg Jr., and M. A. Crowther, "The American Society of Hematology
2011 evidence-based practice guideline for immune thrombocytopenia," Blood, vol. 117, no. 16, pp. 4190-4207, 2011.

[6] D. J. Kuter, M. Rummel, R. Boccia et al., "Romiplostim or standard of care in patients with immune thrombocytopenia," New England Journal of Medicine, vol. 363, no. 20, pp. 1889-1899, 2010.

[7] J. B. Bussel, D. J. Kuter, V. Pullarkat, R. M. Lyons, M. Guo, and J. L. Nichol, "Safety and efficacy of long-term treatment with romiplostim in thrombocytopenic patients with chronic ITP," Blood, vol. 113, no. 10, pp. 2161-2171, 2009.

[8] A. Contis, E. Lazaro, C. Greib, J.-L. Pellegrin, and J.-F. Viallard, "Romiplostim as early treatment for refractory primary immune thrombocytopenia," International Journal of Hematology, vol. 98, no. 5, pp. 520-524, 2013.

[9] G. Tagariello, R. Sartori, P. Radossi, N. Maschio, R. Risato, and R. Stasi, "Romiplostim for the early management of severe immune thrombocytopenia unresponsive to conventional treatment," British Journal of Haematology, vol. 157, no. 2, pp. 256-258, 2012.

[10] N. de Prost, A. Parrot, C. Picard et al., "Diffuse alveolar haemorrhage: factors associated with in-hospital and longterm mortality," European Respiratory Journal, vol. 35, no. 6, pp. 1303-1311, 2010.

[11] F. M. von Ranke, G. Zanetti, B. Hochhegger, and E. Marchiori, "Infectious diseases causing diffuse alveolar hemorrhage in immunocompetent patients: a state-of-the-art review," Lung, vol. 191, no. 1, pp. 9-18, 2013.

[12] C. Rabe, B. Appenrodt, C. Hoff et al., "Severe respiratory failure due to diffuse alveolar hemorrhage: clinical characteristics and outcome of intensive care," Journal of Critical Care, vol. 25, no. 2, pp. 230-235, 2010.

[13] S. Das, S. Cherian, W. Hamarneh et al., "Diffuse alveolar hemorrhage secondary to idiopathic thrombocytopenic purpura; an extremely rare presentation," Chest, vol. 142, no. 4, p. 469A, 2012. 
[14] H. R. T. Hashmi, S. Venkatram, and G. Diaz-Fuentes, "A case report of an elderly woman with thrombocytopenia and bilateral lung infiltrates," Medicine, vol. 94, no. 50, article e2235, 2015.

[15] M. Mizoguchi, K. Kazuhiro, M. Naoto, K. Fukutani, and M. Yukio, "A case of idiopathic thrombocytopenic purpura involving diffuse alveolar hemorrhage," Journal of the Yonago Medical Association, vol. 67, no. 1-2, pp. 9-16, 2016.

[16] K. Okazuka, M. Masuko, Y. Matsuo et al., "Successful treatment of severe newly diagnosed immune thrombocytopenia involving an alveolar hemorrhage with combination therapy consisting of romiplostim, rituximab and vincristine," Internal Medicine, vol. 52, no. 11, pp. 1239-1242, 2013.

[17] M. Uchiyama, A. Hattori, T. Tanaka et al., "Acute idiopathic thrombocytopenic purpura complicated with diffuse alveolar hemorrhage in an elderly patient," Internal Medicine, vol. 48, no. 16, pp. 1449-1452, 2009.

[18] Y. Shirasugi, K. Ando, S. Hashino et al., "A phase II, openlabel, sequential-cohort, dose-escalation study of romiplostim in Japanese patients with chronic immune thrombocytopenic purpura," International Journal of Hematology, vol. 90, no. 2, pp. 157-165, 2009. 


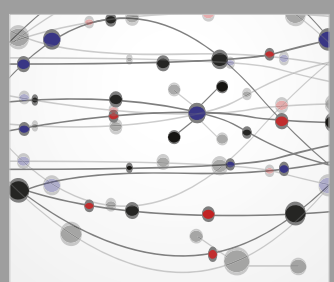

The Scientific World Journal
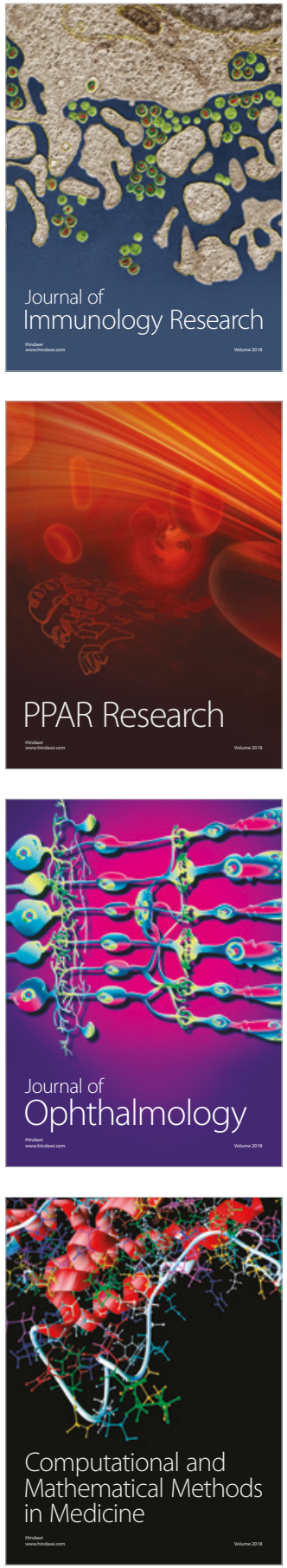

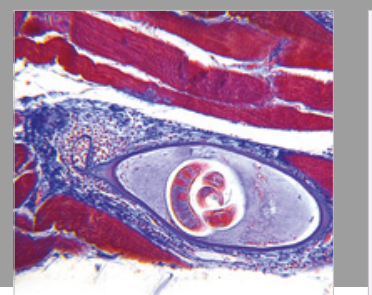

Gastroenterology Research and Practice

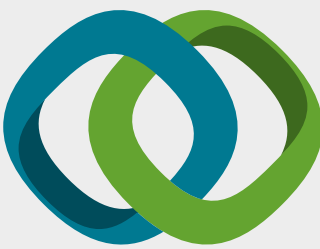

\section{Hindawi}

Submit your manuscripts at

www.hindawi.com
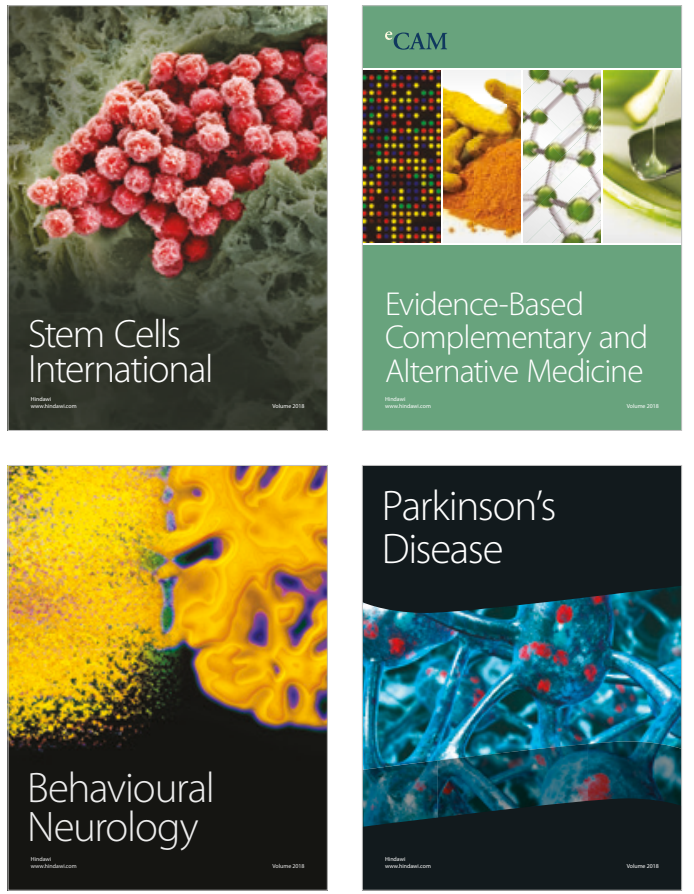

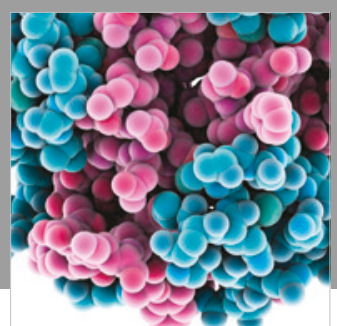

ournal of

Diabetes Research

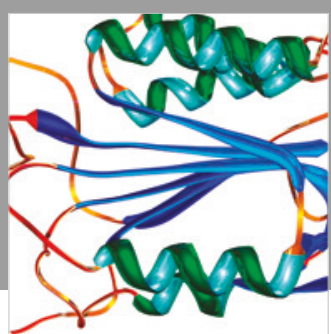

Disease Markers
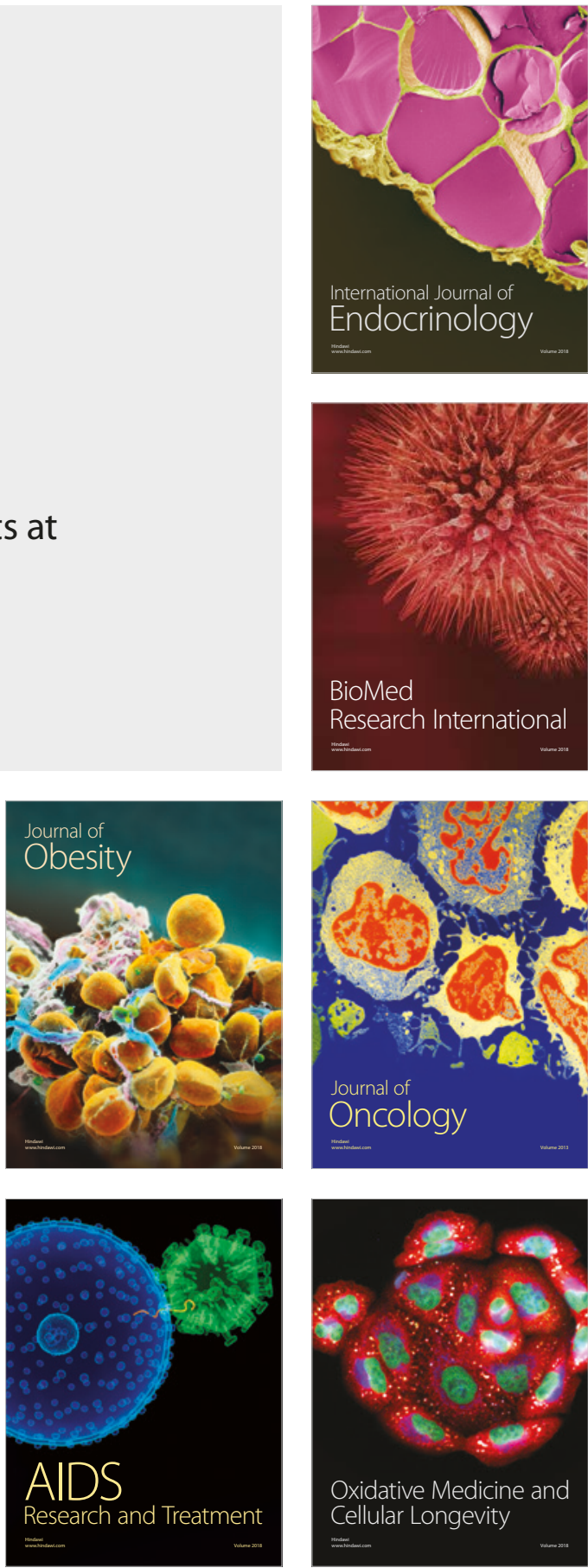